\title{
Coping with change
}

\section{Carmenza Robledo brought together a diverse group of experts from resource management to information technology and policy to assess how forest ecosystems help African rural communities cope with extreme weather events.}

\section{What was the impetus for this project? What was the main objective of the work at the beginning of the project?}

The aim of the research project was to look at how climate change is perceived at the local level, how communities cope with climate change, and the extent to which these strategies are sustainable and relate to ongoing or planned development projects. All members of the research group belong to institutions involved with scientific research and development cooperation. We developed a tool called CRiSTAL (Community-based Risk Screening Tool - Adaptation and Livelihoods) through an iterative process between scientists and local people that allowed us to evaluate people's experience and responses. The results came from three case studies in Zambia, Mali and Tanzania, and demonstrate the links between climate change and forests. The forests offer food and shelter to communities affected by climate change, but of course also suffer directly from the impacts of climate change.

\section{意}
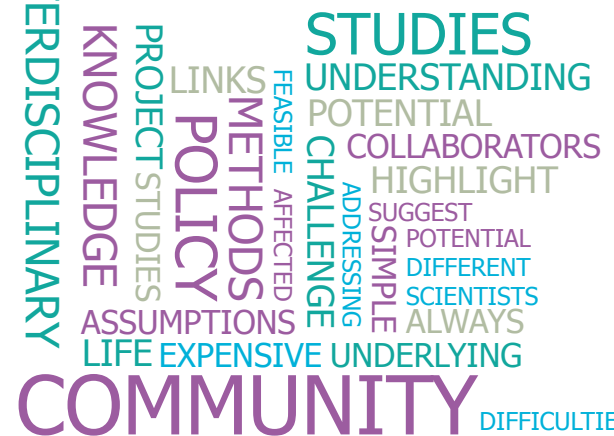

DIFFICULTIES

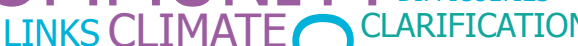
LINKS CLIMATE

ADAPTATION

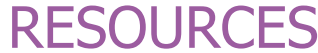

INSTRUCTIONS

INVOLVED

BACKGROUND

COMMUNITY-BASED $C$

RELATE

EXPERTS

TOOL 吕

LONG i⿱

GRANTED

COMMON

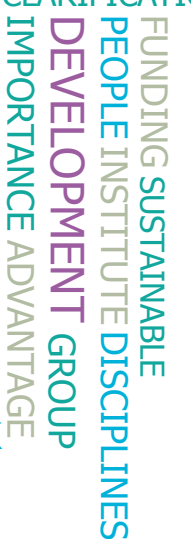

How did you go about finding suitable collaborators?

We had a wide available network of experts and community leaders who were able to help us find collaborators. Four institutions participated in the development of CRiSTAL. Three of these, Intercooperation -

Swiss Foundation for Development and International Cooperation, the International Institute for Sustainable Development, and the International Union for Conservation of Nature (IUCN), participated in the field work for this project. Both Intercooperation and IUCN have long-term collaborations in the countries where the case studies took place.

Did any difficulties arise in working with a team of experts with different research backgrounds and perspectives?

A major challenge was to develop a common understanding of the role of the different disciplines in clarifying the links between climate change and development cooperation. To reach a common ground it was key to have a wide dialogue between partners and researchers, including scientific topics as well as cultural background. To achieve this it was necessary to promote sensitivity for 'the other view. When someone has been working in a discipline for a long time they are not necessarily sensitive to the views and understandings of others, and tend to take one's underlying assumptions for granted.

What was the highlight of working with an interdisciplinary team?

The cross-fertilization between disciplines allows you to face difficulties in understanding. Through this challenging process it is possible to increase knowledge, enabling permanent enrichment. This maximizes the outcome of having different experts at the table.

\section{Any surprises?}

A very positive surprise was the high level of understanding of changes in climate variability, its causes and potential effects, and the ideas for potential 'adaptation and mitigation measures' by the local communities. Even if this understanding was focused on local circumstances, there was a large overlap between scientific and community knowledge. As long as scientists communicated things in simple words, people in the communities were able to understand the complexity of climate modelling.

Did you learn any lessons about interdisciplinary collaboration from this project that would benefit others trying to do similar work?

I have been working in interdisciplinary teams my whole professional life and have a very interdisciplinary background. I think that having an interdisciplinary or, even better, a transdisciplinary approach is crucial to addressing climate change. In the case of this particular project, I would like to highlight the importance of two aspects: the great opportunity for improving knowledge through clarification and challenge of underlying assumptions, and the importance of something as simple as agreeing on the same working definitions when forming an interdisciplinary team.

\section{Was it difficult to get financial} support and what would you suggest to researchers looking for funding to carry out interdisciplinary work?

Yes, it was. Our institutions co-financed part of the research. However, funding research on addressing climate change in the context of development cooperation is becoming more popular, and in general over the past ten years there has been an improvement in funding for interdisciplinary research. But the design of methods is very complex and the time needed for clarification and common understanding implies that this kind of research requires more resources: this makes interdisciplinary research more expensive and funding institutions don't always see the advantages.

\section{Any final thoughts?}

If we really take climate change seriously, then interdisciplinary research is needed to find feasible ways to address it. A holistic approach needs to be included in scientific discussions.

\section{INTERVIEW BY MONICA CONTESTABILE}

This Beyond Boundaries is based on the work by Carmenza Robledo and colleagues, published in Forest Policy Econ. doi:10.1016/j.forpol.2011.04.006 (2011). 